\title{
HUBUNGAN ANTARA KEPEMIMPINAN KEPALA SEKOLAH DENGAN HASIL KINERJA GURU SD NEGERI DI KECAMATAN PERCUT SEI TUAN
}

\author{
Demmu Karo-Karo, Nelly Susanti \\ Surel:demmukarokaro@gmail.com
}

\begin{abstract}
This study aims to determine the relationship between the leadership of school principals and the results of the performance of public elementary school teachers in Percut Sei Tuan District. The research method used is a survey method with a type of quantitative research. To obtain the required data using a data collection tool in the form of documentation and questionnaires. Research in the Elementary School of Percut Sei Tuan as many as 66 schools. The number of samples is 6 schools based on the purposive sampling technique of $10 \%$ while the sample objects are 46 teachers. Based on data analysis, obtained an overview of the principal's leadership in the medium category at $48 \%$ and the teacher's performance in the medium category by 55\%. The results of the correlation analysis between the leadership of the principal with the results of the teacher's performance obtained a value of rcount $=0,733$ with rtable $=0,291$ at the level of confidence of $95 \%$. Thus the calculated value is greater than the rtable value, so the correlation is very significant. Test the hypothesis with the t test obtained tcount $=7.148$ with ttable 1.680 at the confidence level of $95 \%$.
\end{abstract}

Keywords: Leadership, Principal, Teacher Performance Results

\begin{abstract}
ABSTRAK
Penelitian ini bertujuan untuk mengetahui hubungan antara kepemimpinan kepala sekolah dengan hasil kinerja guru SD Negeri di Kecamatan Percut Sei Tuan. Metode penelitian yang digunakan adalah metode survey dengan jenis penelitian kuantitatif. Untuk memperoleh data yang diperlukan menggunakan alat pengumpulan data berupa dokumentasi dan angket. Penelitian di SD sekecamatan Percut Sei Tuan sebanyak 66 sekolah. Jumlah sampel sebanyak 6 sekolah berdasarkan teknik purposive sampling 10\% sedangkan objek sampelnya sebanyak 46 guru. Berdasarkan analisis data, diperoleh gambaran kepemimpinan kepala sekolah dalam kategori sedang sebesar $48 \%$ dan hasil kinerja guru dalam kategori sedang sebesar 55\%. Hasil analisis korelasi antara kepemimpinan kepala sekolah dengan hasil kinerja guru diperoleh nilai korelasi $r_{\text {hitung }}=0,733$ dengan $r_{\text {tabel }}=0,291$ pada taraf kepercayaan $95 \%$. Dengan demikian nilai $\mathrm{r}_{\text {hitung }}$ lebih besar daripada nilai $r_{\text {tabel }}$ maka korelasi sangat signifikan. Uji hipotesis dengan uji $t$ diperoleh $\mathrm{t}_{\text {hitung }}=7,148$ dengan $\mathrm{t}_{\text {tabel }} 1,680$ pada taraf kepercayaan $95 \%$.
\end{abstract}

Kata kunci: Kepemimpinan, Kepala Sekolah, Hasil Kinerja Guru.

\section{PENDAHULUAN}

Pendidikan yang bermutu dan berkualitas tentunya akan menghasilkan sumber daya manusia yang dapat mengoptimalkan potensi sumber daya lain. Guru sebagai suatu 
asset sumber daya manusia merupakan salah satu komponen penting dalam proses pembelajaran di sekolah. Guru sebagai pendidik profesional memiliki tugas utama mendidik, mengajar, membimbing, mengarahkan, melatih, menilai, dan mengevaluasi peserta didik. Oleh karena itu, seorang guru yang profesional dituntut memiliki beberapa kemampuan dan keterampilan tertentu. Guru diharapkan mampu melaksanakan tugas-tugas dan fungsinya dengan baik demi tercapainya tujuan pendidikan nasional.

Untuk mencapai tujuan pendidikan tersebut dibutuhkan hasil kinerja guru yang optimal dan berkualitas. Karena kinerja guru yang optimal dan berkualitas sangat menentukan dalam usaha peningkatan hasil belajar peserta didik secara khusus dan mutu pendidikan secara umum. Seorang guru dituntut untuk dapat memberikan kontribusi yang sangat besar terhadap pendidikan dilingkungan sekolah dimana ia bertugas terutama dalam hal belajarmengajar, karena keberhasilan siswa sangat ditentukan oleh kinerja guru yang professional dalam menjalankan tugas, fungsi dan peranannya sebagai penddidik di sekolah.

Berdasarkan observasi yang telah dilakukan, banyak kendala yang muncul yang menyebabkan kinerja guru kikatakan kurang baik, seperti: beberapa guru langsung pulang setelah pembelajaran di kelas selesai, guru masih ada yang terlambat datang kesekolah, guru masih terlambat masuk kedalam kelas walaupun guru tersebut sudah berada di sekolah, guru masih banyak yang kurang memahami mengimplementasi kurikulum yang sedang berlaku (kurikulum 2013). Kemudian siswa kelas V SD mengatakan saat mengajar, guru masih sering marah-marah dikelas, guru meninggalkan bahan dan menyuruh peserta didik mencatat, jarang memeriksa pekerjaan sekolah yang ditugaskan dirumah (PR) dan masih ada guru jarang memberikan tugas peserta didik di rumah. Hal ini menunjukkan bahwa guru masih kurang bertanggung jawab dengan profesinya. Sedangkan hasil wawancara yang dilakukan dengan guru-guru dikatakan bahwa kepala sekolah belum menerapkan fungsi kepemimpinan secara optimal untuk memimpin bawahannya. Karena banyak dari kebijakan yang dilakukan oleh kepala sekolah bukan berasal dari pemikiran dari seorang kepala sekolah selaku pemimpin, tetapi kebijakan tersebut didasari oleh pemikiran guru selaku bawahannya.

Agar memiliki hasil kinerja guru yang optimal dan berkualitas, kepemimpinan kepala sekolah memiliki pengaruh dalam mencapai tujuan pendidikan di lingkungan sekolah. Sekolah juga membutuhkan figur seorang pemimpin yang siap bekerja keras untuk dapat memajukan sekolah, agar dapat meningkatkan mutu pendidikan di 
lingkungan sekolah yang dipimpinnya.

Kinerja guru akan optimal, bila diintegrasikan dengan komponen sekolah, baik kepala sekolah maupun sarana prasarana serta kerja yang memadai dari guru. Kepemimpinan kepala sekolah yang efektif akan tercipta apabila kepala sekolah memiliki sifat, perilaku dan keterampilan yang baik untuk memimpin sebuah organisasi sekolah. Kepala sekolah harus mampu mempengaruhi semua orang yang terlibat dalam proses pendidikan terutama guru, dan pada akhirnya mencapai tujuan dan kualitas sekolah. Kepemimpinan kepala sekolah yang baik apabila guru dapat merasakan dalam pelaksanaannya tanpa merupakan perintah atau paksaan melainkan merupakan tuntutan tugas yang harus dilaksanakan dengan penuh tanggung jawab agar hasil belajar peserta didik dapat tercapai sesuai dengan tujuan pendidikan nasional.

\section{METODE PENELITIAN}

Penelitian ini menggunakan metode survey, dengan secara langsung ke sekolah untuk memperoleh data-data yang dibutuhkan untuk mengungkapkan kepemimpinan kepala sekolah dan hasil kinerja guru. Sebagai pupulasi sebanyak 56 sekolah. Jumlah sampel sebanyak 6 sekolah berdasarkan teknik purposive sampling $10 \%$ sedangkan objek sampelnya sebanyak 46 guru. Penarikannya dilakukan secara acak (random).
Untuk memperoleh data yang diperlukan diedarkan angket kepada kepala sekolah dan setiap guru yang yang ditetapkan sebagai sampel.

\section{HASIL PENELITIAN DAN PEMBAHASAN}

Pada bagian ini akan dideskripsikan gambaran mengenai hubungan antara kepemimpinan kepala sekolah dengan hasil kinerja guru SD Negeri di Kecamatan Percut Sei Tuan tahun ajaran 2017/2018.

Data pada variabel kepemimpinan kepala sekolah dengan menggunakan instrumen yang berbentuk angket. Instrumen angket, diisi oleh 46 responden yang memiliki 27 butir pernyataan. Setiap butir pernyataan memiliki empat alternatif jawaban. Berdasarkan perhitungan statistik dasar diperoleh rata-rata (mean) 99.89. Data yang diperoleh selanjutnya di buat tabel distribusi frekuensi yang secara singkat dapat dilihat pada tabel 1

Tabel 1. Distribusi Frekuensi

\begin{tabular}{c|c|c|c}
\hline No. & $\begin{array}{c}\text { Kelas } \\
\text { Interval }\end{array}$ & $\mathbf{f}$ & Persentase \\
\hline 1. & $73-77$ & 2 & $4 \%$ \\
\hline 2. & $78-82$ & 0 & $0 \%$ \\
\hline 3. & $83-87$ & 1 & $2 \%$ \\
\hline 4. & $88-92$ & 5 & $11 \%$ \\
\hline 5. & $93-97$ & 6 & $13 \%$ \\
\hline 6. & $98-102$ & 10 & $22 \%$ \\
\hline 7. & $103-107$ & 16 & $35 \%$ \\
\hline 8. & $108-112$ & 6 & $13 \%$ \\
\hline \multicolumn{2}{r}{ Jumlah } & $\mathbf{4 6}$ & $\mathbf{1 0 0 \%}$ \\
\hline
\end{tabular}

Berdasarkan tabel frekuensi di atas, dapat diketahui bahwa kelas interval 103-107 merupakan interval yang memiliki frekuensi guru 
terbanyak yaitu sejumlah 16 guru dengan presentase 35\%. Selain itu, interval yang memiliki frekuensi paling rendah adalah interval 83-87 dengan jumlah 1 guru dengan presentase 2\%. Gambaran tabel distribusi frekuensi kepemimpinan kepala sekolah dapat dilihat pada histogram dibawah ini.

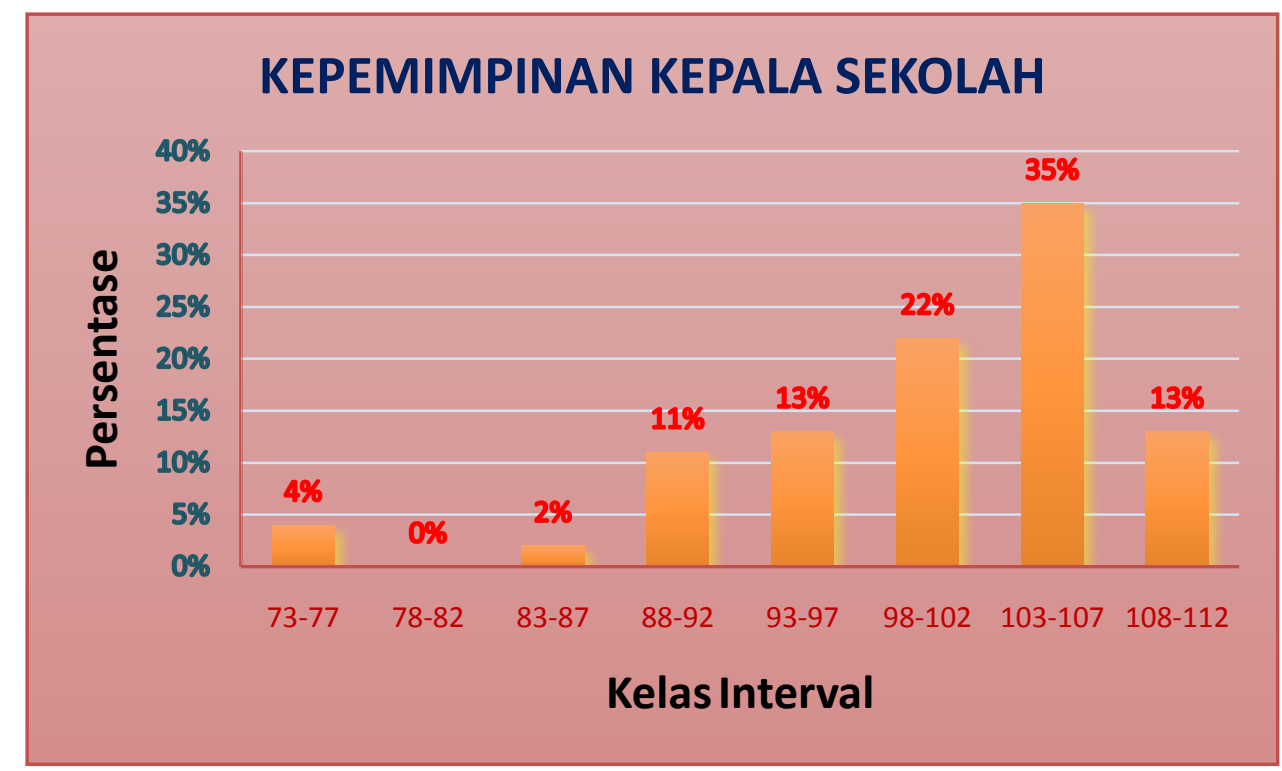

\section{Gambar 1. Histogram Distribusi Kepemimpinan Kepala Sekolah}

Berdasarkan hasil uji hipotesis menunjukkan bahwa terdapat hubungan yang positif dan signifikan antara kepemimpinan kepala sekolah dengan hasil kinerja guru SD Negeri di Kecamatan Percut Sei Tuan. Hal ini ditunjukkan dari besarnya harga $\mathrm{r}_{\text {hitung }}$ yang lebih besar dari $\mathrm{r}_{\text {tabel }}$, yaitu $0.733>0.291$, dan dibuktikan dengan hasil uji $t$, dimana $t_{\text {hitung }}>t_{\text {tabel }}$ yaitu $7.148>1.680$.

Dengan demikian dapat diasumsikan bahwa semakin baik kepemimpinan kepala sekolah maka cenderung semakin baik pula hasil kinerja gurunya, sebaliknya semakin tidak baik kepemimpinan kepala sekolah maka cenderung semakin tidak baik pula hasil kinerja gurunya. Berdasarkan analisis deskriptif kepemimpinan kepala sekolah pada penelitian ini termasuk dalam kategori sedang.

\section{Pembahasan}

Indikator untuk pencapaian keberhasilan kepemimpinan kepala sekolah, kepala sekolah harus 
menguasai kelima kompetensikompetensi yang harus dimiliki kepala sekolah, namun kenyataannya dalam penelitian ini kepala sekolah belum mampu menguasai kelima kompetensi yang harus dikuasai kepala sekolah. Misalnya, kepala sekolah belum mampu menguasai kompetensi manajerial yang merupakan kompetensi penting dalam kepemimpinan kepala sekolah. Sebagai contoh pada kompetensi manajerial, kepala sekolah harus mampu melakukan perencanaan, pengorganisasian, pengawasan, dan pengendalian dalam memimpin sebuah sekolah. Bagaimana mungkin kepala sekolah mampu menjadi kepala sekolah jikalau tidak menguasai kompetensi manajerial ini? Program sekolah tidak akan berjalan dengan baik. Begitu pula dengan kompetensi-kompetensi kepemimpinan kepala sekolah yang lainnya. Sehingga ini menjadi salah satu penyebab hasil kepemimpinan kepala sekolah dalam penelitian ini termasuk dalam kategori sedang, yang berarti masih perlu peningkatan kepemimpinan kepala sekolah.

Begitu pula dengan indikator untuk pencapaian keberhasilan hasil kinerja guru, guru harus menguasai keempat kompetensi-kompetensi yang harus dimiliki guru, namun kenyataannya guru belum mampu menguasai ke-empat kompetensi yang harus dikuasai oleh guru, sehingga ini juga menjadi salah satu penyebab hasil kinerja guru termasuk dalam kategori sedang, yang berarti kinerja guru juga perlu ditingkatkan.
Berdasarkan teori Wahyudi (2012:34) mengutarakan bahwa, "kepemimpinan kepala sekolah dapat mempengaruhi dan mengarahkan bawahan (para guru) untuk mencapai tujuan sekolah melalui kegiatankegiatan, (a) meningkatkan partisipasi anggota dalam menyusun program sekolah, (b) menciptakan iklim kerja yang kondusif, (c) mendelegasikan sebagian tanggung jawab dan mengikutsertakan guruguru untuk membuat keputusan, (d) mendorong kinerja anggota dan memberikan kesempatan guru untuk tampil.

Dengan demikian berdasarkan hasil penelitian yang didapat, maka dapat disimpulkan bahwa terdapat hubungan yang positif antara kepemimpinan kepala sekolah dengan hasil kinerja guru SD di Kecamatan Percut Sei Tuan.

\section{SIMPULAN}

Dari hasil analisis data yang telah dikemukakan maka kesimpulan yang dapat diperoleh adalah :

a. Kepemimpinan kepala sekolah SD Negeri di Kecamatan Percut Sei Tuan berada pada kategori sedang dengan persentase $48 \%$.

b. Hasil kinerja guru SD Negeri di Kecamatan Percut Sei Tuan berada pada kategori sedang dengan persentase $55 \%$.

c. Terdapat hubungan yang positif antara kepemimpinan kepala sekolah dengan hasil kinerja guru dengan rhitung > rtabel (0.733> 0.291). Selain itu, hasil perhitungan uji $t$ dibuktikan 
dengan $t_{\text {hitung }}>t_{\text {tabel }}$ yaitu 7.148 $>1.680$, terdapat hubungan yang signifikan antara kepemimpinan kepala sekolah dengan hasil kinerja guru SD Negeri di Kecamatan Percut Sei Tuan.

\section{DAFTAR RUJUKAN}

Arikunto, Suharsimi. 2014. Prosedur Penelitian Suatu Pendekatan Praktik. Jakarta: Rineka Cipta Agung, $\quad 2010$. Meningkatkan Kreativitas Pembelajaran Bagi Guru. Jakarta: Bestari Buana Murni

Basri, Hasan. 2014. Kepemimpinan Kepala Sekolah. Bandung: Pustaka Setia

Departemen Pendidikan Nasional. 2012. Kamus Besar Bahasa Indonesia. Jakarta: Gramedia Pustaka Utama

Dewi, Chrisyanti, Irra. 2013. Teori Kepemimpinan Managerial. Jakarta: Prestasi Pustakakaraya Hutabarat, Wesly. 2015. Mengukur Kinerja Guru Profesional. Jakarta: Halaman Moeka

Kadir. 2015. Statistika Terapan (Konsep, Contoh dan Analisis Data dengan Program SPSS/Lisrel dalam Penelitian). Jakarta: Rajawali Pers

Makawimbang. 2012. Kepemimpinan Pendidikan Yang Bermutu. Bandung: Alfabeta.

Mulyasa. 2010. Standar Kompetensi dan Sertifikasi Guru. Bandung: Remaja Rosdakarya
Muslich, Masnur. 2009. Sertifikasi Guru Menuju Profesionalisme Pendidik. Jakarta: Bumi Aksara

Noor, Juliansyah. 2011. Metodologi Penelitian. Jakarta: Kencana

Riduwan. 2010. Skala Pengukuran Variabel-Variabel Penelitian. Bandung: Alfabeta

Satriadi. 2016. Pengaruh Kepemimpinan Kepala Sekolah Terhadap Kinerja Guru. Dalam Jurnal Jurnal Benefita 1(3) Oktober 2016 (123-133)

Silitonga, P.M. 2014. Statistik Teori dan Aplikasi Dalam Penelitian. Medan: Unimed Press

Sudarma, Momon. 2013. Profesi Guru. Jakarta: Raja Grafindo Persada

Sugiyono. 2016. Metode Penelitian Pendidikan. Bandung: Alfabeta Sulistiya, Mukhamad. 2013. "Pengaruh Kepemimpinan Kepala Sekolah Terhadap Kinerja Guru”. Dalam Jurnal Ilmiah Pendidikan Ekonomi IKIP Veteran Semarang Vol. 1 No. 2, Oktober 2013

Supardi. 2014. Kinerja Guru. Jakarta: Raja Grafindo Persada Undang-undang Republik Indonesia No.20 Tahun 2003. Sistem Pendidikan Nasional. Jakarta: Departemen Pendidikan Nasional

Wahyudi. 2012. Kepemimpinan Kepala Sekolah Dalam Organisasi Pembelajaran. Bandung: Alfabeta 